\title{
AVALIAÇÃO DE UMA SEQUENCIA DE ENSINO INVESTIGATIVA SOBRE POLUIÇÃO APLICADA NO ENSINO MÉDIO DE ALUNOS JOVENS E ADULTOS
}

\author{
ASSESSMENT OF AN EDUCATIONAL INVESTIGATIVE \\ SEQUENCE ABOUT POLLUTION IN \\ ADULT HIGH SCHOOL STUDENTS
}

EVALUACIÓN DE UNA SECUENCIA EDUCATIVA DE
INVESTIGACIÓN SOBRE LA CONTAMINACIÓN EN
ESTUDIANTES ADULTOS DE LA ESCUELA SECUNDARIA

William Kleber Martins Vieira ${ }^{1}$
Roberta Conceição Silva Moraes ${ }^{2}$
Martha CRistina Motta Godinho-Netto ${ }^{3}$
${ }^{1}$ Instituto de Ciências Biomédicas da Universidade de São Paulo (USP).
São Paulo/SP-Brasil
2E. E. João Alvares Siqueira Bueno. Guarulhos/SP-Brasil
${ }^{3}$ Instituto Federal de Educação, Ciência e Tecnologia de
São Paulo (IFSP). São Paulo/SP- Brasil

REsumo No Brasil, a aplicação da abordagem investigativa no ensino de ciências e disciplinas científicas constitui-se em um dos eixos formativos previstos na Base Nacional Comum Curricular (BNCC). No entanto, o ensino de ciências e biologia por investigação não está incorporado de maneira abrangente ao planejamento escolar, e sua inclusão configura-se um desafio muito grande para os professores. Na Educação de Jovens e Adultos (EJA), essa situação se potencializa, pois não há diretrizes de ensino específicas descritas nos documentos oficiais. Este trabalho apresenta os resultados de uma avaliação da aplicação de uma sequência de ensino investigativa (SEI) sobre "Poluição", aos alunos de uma turma de Jovens e Adultos (EJA) de uma escola pública brasileira. Avaliaram-se os impactos nos seguintes aspectos: motivação para aprendizagem, experiência ao participar e conhecimento metacognitivo. Os resultados indicam a ampliação da participação, demonstração de interesse e compromisso, aumento da satisfação, confiança, interação e colaboração dos alunos.

Palavras-chave: Ensino por investigação; Biologia; Ciências; EducaÇão de jovens e ADULTOS; ENSINO MÉDIO.

Comunicações $\mid$ Piracicaba $\mid$ v. $26 \mid$ n. $2 \mid$ p. 161-177| maio-ago. 2019161 
Abstract In Brazil, the application of the investigative approach in science teaching and scientific disciplines constitutes one of the formative axes foreseen in the National Common Curricular Base (BNCC). However, the teaching of science and biology by research is not comprehensively incorporated into school planning, and its inclusion configures a very large challenge for teachers. In Youth and Adult Education (EJA), this situation is potentialized because there are no specific teaching guidelines described in the official documents. The present work presents the results of an evaluation of the application of an investigative teaching sequence (SEI) on "pollution", to students of a youth and adult class (EJA) of a public school Brazilian. The impacts were evaluated in the following aspects: motivation for learning, experience in participating and metacognitive knowledge. The results indicate the expansion of participation, demonstration of interest and commitment, increased satisfaction, confidence, interaction and collaboration of the students.

Keywords: Investigative teaching; Biology education; Science education; Adult educaTION; SECONDARY SCHOOLS.

Resumen En Brasil, la aplicación del enfoque investigativo en la enseñanza de ciencias y disciplinas científicas se constituye en uno de los ejes formativos previstos en la Base Nacional Común Curricular (BNCC). Sin embargo, la enseñanza de ciencias y biología por investigación no está incorporada de manera integral a la planificación escolar y su inclusión se constituye un desafío muy grande para los profesores. En la Educación de Jóvenes y Adultos (EJA), esa situación se potencializa, pues no hay directrices de enseñanza específicas descritas en los documentos oficiales. El presente trabajo presenta los resultados de una evaluación de la aplicación de una secuencia de enseñanza investigativa (SEI) sobre "Contaminación", a los alumnos de una clase de jóvenes y adultos (EJA) de una escuela pública brasileña. Se evaluaron los impactos en los siguientes aspectos: motivación para el aprendizaje, experiencia al participar y conocimiento metacognitivo. Los resultados indican la ampliación de la participación, demostración de interés y compromiso, aumento de la satisfacción, confianza, interacción y colaboración de los alumnos.

Palabras clave: Enseñanza por la investigación; Educación en biología; Educación CIENTíficA; EdUCACiÓN DE JÓvENES Y ADULTOS; Escuela SECUNDARIA.

\section{INTRODUÇÃo}

No Brasil, a aplicação da abordagem investigativa no ensino de ciências e nas disciplinas científicas (física, química e biologia) constitui-se em um dos eixos formativos previstos na proposta da Base Nacional Comum Curricular (BNCC) (BRASIL, 2016). Este documento define que a investigação deve permitir o engajamento dos estudantes, levando-os a formular questões, identificar e investigar problemas, propor e testar hipóteses, elaborar argumentos e explicações, planejar e realizar atividades experimentais e pesquisas de campo, relatar e comunicar conclusões (a partir de dados e informações) e buscar a resolução de problemas práticos que envolvam conhecimentos das Ciências da Natureza (BRASIL, 2016). 
No entanto, de acordo com Sá et al. (2007), o ensino de Ciências e de Biologia por investigação não está incorporado de maneira abrangente ao planejamento escolar brasileiro e sua inclusão na rotina educacional configura-se um desafio muito grande para os professores. Muitas vezes, os docentes sentem-se inseguros quanto à efetividade das atividades investigativas como estratégia didática e outras vezes quanto à sua própria capacidade de realizar as atividades de forma adequada (SÁ et al., 2007).

Quando se considera o ensino de Biologia na Educação de Jovens e Adultos do Ensino Médio (EJA-EM), que são aqueles alunos que não concluíram os estudos do Ensino Médio no regime regular, Oliveira (2007) ressalta que, apesar das especificidades dessa modalidade de ensino, não há diretrizes específicas definidas nos documentos oficiais e é comum que os docentes utilizem as mesmas diretrizes definidas para o ensino médio regular. Por sua vez, os antigos Parâmetros Curriculares Nacionais (BRASIL, 1997) já estabeleciam que os professores deveriam aplicar estratégias pedagógicas formativas e metodológicas que favorecessem a aprendizagem e a participação desses alunos no seu contexto social, econômico e escolar.

Segundo Oliveira (2007), os professores da EJA-EM acabam não conseguindo estabelecer um equilíbrio entre o currículo e as abordagens metodológicas alternativas e muitas vezes optam por utilizar uma versão compactada da estratégia de ensino tradicional e de forte caráter teórico, usada no ensino médio regular.

\section{CONTEXTUALIZAÇÃO HISTÓRICA}

A fundamentação teórica e a apropriação da perspectiva investigativa como prática do ensino de ciência foram se modificando no decorrer do século XX. Essa mudança estaria intimamente ligada às concepções de investigação científica e, portanto, levando em consideração a discussão da natureza da Ciência nos diferentes momentos e contextos históricos (TRÓPIA, 2011).

A terminologia "investigação" aplicada como estratégia para o ensino de ciências, conforme é utilizada no Brasil, provém da tradução dos termos da língua inglesa inquiry ou enquiry. A inclusão da perspectiva investigativa, no contexto da educação científica, segundo Barrow (2006), teria sido apresentada nos Estados Unidos, no início do século XX por John Dewey (pensador de vanguarda no pragmatismo e na educação progressista dos Estados Unidos), reconhecido como o educador estadunidense mais considerado do século XX (TRÓPIA, 2011).

O cenário político e social em que suas ideias surgiram está associado ao chamado New Deal, política que visava enfrentar o desemprego da classe trabalhadora e a falência das empresas, em decorrência da crise econômica instaurada pela quebra da Bolsa, em 1929. Nessa época, houve uma perda na imagem de "nação autossuficiente" da sociedade norte-americana e uma consequente perda da autoconfiança do povo (CUNHA, 2001).

Segundo Trópia (2011), essa situação derivava da falta de enfrentamento das desigualdades e dos conflitos sociais e reforçava uma constante negligência aos interesses e bem-estar social dos trabalhadores. 
Dewey se inquietava quanto à necessidade de estabelecimento das novas relações de trabalho e se preocupava com a estagnação de instituições sociais que não acompanhavam essas mudanças, inclusive a escola, pois não discutiam os conflitos ético-sociais que emergiam desse contexto (TRÓPIA, 2011). Entretanto, ele acreditava que a educação escolar possibilitaria a construção de uma sociedade mais humanizada, visto que esta seria uma ferramenta poderosa para a democracia (CUNHA, 2001).

Nas concepções de Dewey, a aplicação do método científico como um conjunto de etapas que caracterizam a investigação científica poderia proporcionar a organização do processo pedagógico nas práticas escolares. Isso permitiria superar a ideia de que os alunos aprendem os conceitos técnicos sem entender o modo e a forma de se chegar a eles. Além disso, a aplicação também se caracterizaria como uma maneira de superar a falta de interesse dos alunos para a descoberta das relações desses conceitos com os objetos e atos que lhes são familiares (TRÓPIA, 2011).

Basicamente, Dewey propunha que o ensino poderia ser norteado inicialmente pela definição do problema que permitiria a proposição de uma solução, desenvolvimento e aplicação de teste experimental e construção de conclusões subsequentes (TRÓPIA, 2011).

É importante citar que a incorporação das ideias de Dewey nos Estados Unidos só ocorreu na época da chamada "Guerra Fria", nos anos de 1960. Nessa década, muitos investimentos foram feitos na educação, visando incentivar os jovens a seguirem carreiras científicas. Foi a origem da primeira geração de projetos de ensino em Física, Química, Biologia e Matemática para o ensino médio (KRASILCHIK, 2000).

Já no Brasil, as reformas curriculares no ensino de ciências, no período entre as décadas de 1950 e 60, foram altamente influenciadas por um contexto histórico evidenciado pela industrialização. Esse contexto exigia um progresso da Ciência e Tecnologia altamente dependente de alterações nos currículos, priorizando a formação de jovens pesquisadores que alavancassem o setor no país (KRASILCHIK, 2000). Assim, no final da década de 1960, tentando suprir essa necessidade e demandas da época, instituições como o Instituto Brasileiro de Educação, Ciência e Cultura (IBECC) elaboraram projetos que visavam a melhoria do ensino de ciências nas escolas de nível básico e priorizavam o desenvolvimento de investigações científicas pelos estudantes, por intermédio da introdução do método experimental em sala de aula (BARRA; LORENZ, 1986). Os materiais didáticos utilizados eram produzidos nos EUA e traduzidos e distribuídos no Brasil pela IBECC. Os principais exemplos incluem os históricos livros de biologia Biology Science Curriculum Study (BSCS) com três versões: azul, verde e amarelo. Para a física, foi produzido Physics Science Study Committe (PSSC) e para a química, Chemical Bond Approach (CBA) (BARRA; LORENZ, 1986; BARROW, 2006).

Os materiais didáticos em questão traziam a concepção da investigação científica experimental, inclusive para as Ciências Biológicas. Esses materiais eram fundamentados na vivência do método científico, levando o aluno a "pensar como cientista", a realizar processos de produção da ciência a partir de etapas, como a observação, classificação, inferência, coleta de dados, controle de variáveis, interpretação dos dados e conclusão (BARRA; LORENZ, 1986; BARROW, 2006). 
Entretanto, Krasilchik (2000) ressalta que, a despeito da incorporação da valorização da ciência e da forma de fazer ciência no ensino das diversas disciplinas científicas, os projetos curriculares do período, compreendido entre 1950 e 1970, apresentavam uma visão neutra e distorcida sobre a investigação científica, visão essa que se manteve por um longo período nos materiais das décadas posteriores. Nessa visão neutra da Ciência, acreditava-se na existência de um método fixo (observar, medir e controlar variáveis, analisar os dados em busca de relações e tirar conclusões acerca do fenômeno estudado) capaz de gerar o conhecimento científico em uma sequência linear e indutiva de passos que garantia segurança na obtenção de resultados. Isso era visto como um procedimento definido, testado, confiável e o único capaz de gerar o conhecimento científico.

Além disso, a visão do método não comportava o entendimento da Ciência como sendo influenciada por fatores sociais, políticos ou econômicos. A respeito desse ponto de vista, os pesquisadores ficavam isentos de juízo de valor sobre o que estavam fazendo ou das possíveis consequências de seus atos. Essa visão estava representada nos materiais didáticos utilizados na época que prezavam por desenvolver a racionalidade, a capacidade de fazer observações controladas, preparar e analisar estatísticas e respeitar a exigência de replicabilidade dos experimentos (KRASILCHIK, 2000).

No final da década de 80 e início da década de 90, inicia-se um novo processo de promoção de práticas investigativas no ensino de Ciências, seguindo-se como uma demanda até os dias atuais. Novamente, esse "incentivo" parte de influência externa, especialmente dos Estados Unidos, em que a retomada da abordagem investigativa esteve vinculada com reformas curriculares que buscavam levar a "Ciência para todos" e também da Inglaterra, onde se tentava promover o "entendimento público da Ciência". Ambos os países tinham como foco a alfabetização científica da população, almejando promover um entendimento da influência crescente da Ciência e Tecnologia nos âmbitos políticos, econômicos e sociais (TRÓPIA, 2011).

Nota-se que essas mudanças curriculares assumiram uma nova perspectiva no que tange à investigação como prática no ensino de Ciências, passando a contemplar discussões sobre a natureza da Ciência e as relações das atividades de ensino com o âmbito social, evidenciando a relação entre ciência e sociedade e abrindo margem para discussões e indagações quanto aos possíveis efeitos (positivos ou negativos) das produções científicas (TRÓPIA, 2011).

\section{INVESTIGAÇÃO E OS DOCUMENTOS OFICIAIS DE ENSINO}

No Brasil, as discussões acerca da natureza da Ciência e das relações da Ciência, Tecnologia e Sociedade no ensino são observadas a partir de 1997, com a criação dos Parâmetros Curriculares Nacionais (PCNs) (BRASIL, 1997). Segundo Machado (2013), os PCNs reforçam a necessidade de oportunizar um ensino ancorado em problematização, favorecendo discussões e reflexões amplas sobre temas relevantes e de interesse social. Há também a indicação de uso de temas transversais que viabilizam o trabalho dos conteúdos 
de forma contextualizada, garantindo a apresentação dos aspectos históricos e sociais. A investigação, neste contexto, seria uma característica intrínseca do ensino de Ciências:

O método da redescoberta, com sua ênfase no método científico, acompanhou durante muito tempo os objetivos do ensino de Ciências Naturais, levando alguns professores a, inadvertidamente, identificarem metodologia científica como metodologia do ensino de Ciências Naturais, perdendo-se a oportunidade de trabalhar com os estudantes, com maior amplitude e variedade, processos de investigação adequados às condições do aprendizado e abertos a questões de natureza distinta daquelas de interesse estritamente científico (BRASIL, 1997, p. 20).

Contrapor e avaliar diferentes explicações favorece o desenvolvimento de postura reflexiva, crítica, questionadora e investigativa, de não-aceitação, a priori, de ideias e informações, assim como a percepção dos limites das explicações, inclusive dos modelos científicos, colaborando para a construção da autonomia de pensamento e de ação (BRASIL, 1997, p. 22).

Essa abordagem também é indicada nas Propostas Curriculares para a Educação de Jovens e Adultos, tanto na modalidade do ensino fundamental (BRASIL, 2001) como do ensino médio (RONDÔNIA, 2013). É importante ressaltar que não foi encontrado qualquer documento nacional voltado a Propostas Curriculares do Ensino Médio - EJA, sendo utilizado como referencial uma proposta específica elaborada no Estado de Rondônia (RONDÔNIA, 2013). Esses documentos enfatizam a importância da investigação, como pode ser visto nas citações a seguir, com indicações de como realizar essa abordagem:

$\mathrm{Na}$ investigação de um determinado tema, é muito importante que o aluno não se baseie apenas em observações, mas que utilize outros métodos para obter informações sobre o assunto, como leituras e experimentações. Os dados obtidos em diferentes fontes podem subsidiar discussões e comparações mais detalhadas e também mais relevantes, abrindo espaço para a superação do senso comum, já consolidado entre os adultos e, por isso mesmo, muito frequente em EJA (BRASIL, 2001, p. 81).

A organização do trabalho pedagógico deve ter como fio norteador "a pesquisa como princípio pedagógico", possibilitando que o estudante possa ser protagonista na investigação e na busca de respostas em um processo autônomo de (re) construção de conhecimentos (RONDÔNIA, 2013, p. 20).

Neste contexto, o (a) professor (a) deve propiciar a construção de conceitos e atitudes ao estudante ao trabalhar os eixos articuladores, representação e comunicação, investigação e compreensão, contextualização sociocultural, nessa área, a partir de questionamentos e de problematização daquilo que é observado e vivido para compreender o mundo, a dinâmica de interdependência entre os sistemas que o compõem e suas transformações, percebendo o ser humano como indivíduo e enquanto parte constituinte do universo (RONDÔNIA, 2013, p. 283). 
Mais recentemente, a Base Nacional Comum Curricular (BRASIL, 2016) enfatizou também a preocupação com a realização de processos e práticas em Ciências da Natureza, dentro de uma dimensão investigativa, que propicie a vivência com os modos de produção do conhecimento científico, envolvendo não apenas a aplicação, mas também o estudo de metodologias de elaboração do conhecimento. Em síntese, segundo o documento, a investigação deverá permitir o engajamento dos estudantes, levando-os a formular questões, identificar e investigar problemas, propor e testar hipóteses, elaborar argumentos e explicações, planejar e realizar atividades experimentais e pesquisas de campo, relatar e comunicar conclusões a partir de dados e informações e buscar a resolução de problemas práticos que envolvam conhecimentos das Ciências da Natureza (BRASIL, 2016).

Nesse sentido, uma hipótese a ser considerada é que esse tipo de abordagem poderia responder à demanda observada na análise feita por Soares (2011) apud Barbosa (2015), de alguns trabalhos interligados ao EJA, que enfatiza a busca por práticas educativas que se harmonizem com um sujeito inserido no mundo contemporâneo, consciente, crítico, capaz de opinar, agir, desconstruir e construir a história e o seu espaço. Soma-se a isso o fato de que uma das características marcantes nas atividades investigativas se volta ao processo de aprendizagem dos estudantes, focando a aquisição de conteúdos científicos, capazes de permitir a inserção na cultura científica e o desenvolvimento de habilidades necessárias para o "fazer científico" (TONINDANDEL, 2013).

É importante salientar, para que uma atividade prática seja entendida como investigativa, deve-se, entre outros possíveis aspectos, garantir aos alunos o acesso aos dados (no sentido de observação, fato, resultado de experimento ou razão/justificativa) e a resolução de problemas com o uso de teorias como explicação, garantindo a possível articulação entre dados e afirmação (CHINN; MALHORTRA, 2002).

No caso das aulas de Ciências, isso implicaria o desenvolvimento de um modelo de ensino que focasse tanto o "aprender Ciência" quanto a "aprendizagem sobre a Ciência", entendendo que isso implica compreender a base do conhecimento teórico da disciplina, como são explicados os fenômenos naturais, como "funciona" a ciência, suas formas de raciocínio e justificação e perceber a relação complexa entre ciência, tecnologia e sociedade (GUISASOLA, FURIÓ E CEREBIO, 2006).

Todavia, é interessante notar que, apesar desses objetivos estarem inseridos em diversos currículos nos mais variados países, as pesquisas em educação e ciências demonstram que eles teriam sido alcançados em uma proporção muito pequena. Ademais, as abordagens que têm como eixo cognitivo a resolução de problemas e a argumentação são aplicadas em poucas escolas e por poucos docentes (GUISASOLA, FURIÓ E CEREBIO, 2006; TONIDANDEL, 2013).

\section{PROBLEMAS DE INVESTIGAÇÃO}

Nesse contexto, seria preciso aprofundar o entendimento das particularidades inerentes à elaboração e aplicação de atividades investigativas adequadas a um público estudantil 
específico nas quais fossem garantidos os pressupostos do ensino por investigação, bem como, atender a uma demanda crescente pela contextualização e protagonismo do aluno no ensino de Biologia. Dessa forma, esta pesquisa se propôs a avaliar, sob a perspectiva da professora e dos alunos, a aplicação das atividades investigativas no processo de ensino de Biologia de uma turma de EJA-EM.

\section{Desenvolvimento}

Este trabalho configurou-se como uma pesquisa de intervenção pedagógica encoberta que envolveu o planejamento e a implementação de interferências em sala de aula, visando produzir mudanças nos processos de aprendizagem dos sujeitos participantes com posterior análise dos resultados (DAMIANI et al., 2013). Nela, os procedimentos do estudo ficaram ocultos aos participantes durante parte do processo (tendo em vista minimizar alterações no comportamento dos sujeitos participantes que pudessem alterar o grau de confiabilidade dos resultados), garantindo-se todas as prerrogativas legais definidas na Resolução ${ }^{\circ}$. 510 , de 7 de abril de 2016 (BRASIL, 2016). A aprovação do trabalho foi feita pelo Comitê de Ética em Pesquisa do Instituto Federal de Educação, Ciência e Tecnologia de São Paulo (CAAE: 58835016.1.0000.5473).

A pesquisa foi realizada em uma turma ofertada no período noturno, composta de onze alunos, com faixa etária variando entre 18 anos e 60 anos, cursando o $1^{\circ}$. ano da EJA-EM de uma escola pública da cidade de Guarulhos, São Paulo/Brasil.

METODOLOGIA DE CARACTERIZAÇÃO DA INSTITUIÇÃO, TURMA E MAPEAMENTO DA ATIVIDADE DOCENTE

A coleta de dados sobre a instituição, turma e alunos foi realizada visando levantar as condições de infraestrutura, organização pedagógica, perfil da turma e dos alunos. Os dados foram obtidos por meio de visita à instituição de ensino e aplicação de questionário específico enviado pela internet, além da entrevista efetuada em encontro presencial.

\section{PRESSUPOSTOS TEÓRICO-PRÁTICOS USADOS NA ELABORAÇÃO DA SEQUÊNCIA DE ENSINO INVESTIGATIVA (SEI)}

As atividades investigativas foram organizadas na forma de uma sequência de ensino investigativa (SEI), incluindo uma aula introdutória de sensibilização e outras cinco aulas duplas de 45 minutos, totalizando 90 minutos por encontro. Em conjunto, a SEI continha uma grande variedade de estratégias didáticas, visando garantir não só a significação do ensino, como também, a oportunidade de geração de momentos de ensino adequados aos pressupostos da aprendizagem por investigação. ${ }^{1}$ A elaboração das atividades levou em

A SEI (orientações para o professor e material do aluno) pode ser obtida com os autores desta pesquisa mediante solicitação.

168 Comunicações | Piracicaba | v. $26 \mid$ n. 2 | p. 161-177 | maio-ago. 2019 
consideração a realidade dos alunos (mais especificamente, do entorno da escola), os obstáculos pedagógicos, descritos pela professora regente, os pressupostos teóricos específicos do ensino por investigação, adaptados de Tonindandel (2013) e Zômpero e Laburú (2011) como: a existência de um problema, a emissão de hipóteses, um planejamento para a realização do processo investigativo, a obtenção de novas informações, a interpretação e a possibilidade de elaborar conclusões e de comunicar ideias. Ademais, na elaboração garantiu-se a existência de diferentes graus de autonomia do aluno, seguindo os graus de liberdade caracterizados por Carvalho (2006) apud Zômpero e Laburú (2011, p. 77).

A escolha do tema "Poluição" (poluentes atmosféricos e seus efeitos no organismo; poluentes da água e do solo; doenças transmitidas pela água e pelo solo; destino do lixo) foi realizada a partir dos assuntos já definidos no planejamento das aulas do $2^{\circ}$. bimestre do $2^{\circ}$. semestre de 2016. Os objetivos gerais propostos para a sequência incluíram objetivos conceituais, procedimentais e atitudinais.

Ressalta-se que a SEI foi elaborada em duas versões: (a) "material do professor" - que apresenta as atividades incluindo as orientações para a aplicação das mesmas e referências complementares e (b) "material do aluno" - que apresenta as atividades a serem aplicadas aos discentes. A elaboração dos dois tipos de material foi considerada importante, pois a despeito das reuniões para orientação e apresentação do material, a aplicação da SEI foi realizada exclusivamente pela professora regente da turma, que não tinha, na ocasião, experiência na aplicação desse tipo de atividades. Dessa forma, a SEI na versão "material do professor" foi elaborada para ampliar a confiança da docente na execução da mesma, além de visar à possibilidade de expandir a aplicação das atividades por outros professores da escola.

Em relação às habilidades e competências, as atividades foram propostas pensando em promover o desenvolvimento da: leitura, interpretação de textos e gráficos, formulação de hipóteses e questões, oralização de ideias e capacidade de trabalhar em grupo.

Os objetivos gerais propostos para a sequência estão listados a seguir:

\section{A) Objetivos Conceituais Gerais}

- Compreender e aplicar os conceitos teóricos discutidos sobre poluição atmosférica, efeitos fisiológicos e monitoramento, poluição da água e doenças de veiculação hídrica e solo (importância, poluição e biorremediação) para a resolução de problemas novos e mais amplos.

\section{B) Objetivos Procedimentais Gerais}

- Elaborar hipóteses;

- Ler e interpretar textos, figuras, tabelas e gráficos;

- Registrar e organizar os dados;

- Classificar e organizar ideias e conceitos;

- Comunicar oralmente e por escrito ideias. 


\section{C) Objetivos Atitudinais Gerais}

- Compreender a importância de ações individuais e coletivas para a diminuição da poluição;

- Promover uma autorreflexão sobre a realização de condutas potencialmente danosas ao ambiente, visando uma mudança de comportamento.

\section{Metodologia DE AVALIAÇÃO DA APLICAÇÃO DA SEI}

A avaliação da aplicação da sequência de ensino investigativa foi realizada por meio da adaptação do instrumento específico proposto por Savi et al. (2010), visando avaliar os seguintes aspectos: 1) motivacional; 2) experiência (sentimentos gerados ao realizar as atividades que poderiam influenciar o ensino e a aprendizagem) e 3) metacognitivo (entendimento dos próprios alunos quanto aos impactos promovidos pelas atividades em seu conhecimento conceitual, levando em consideração os temas tratados nas atividades).

Incorporaram-se quatro categorias de possíveis estratégias consideradas importantes na motivação da aprendizagem, sendo elas: atenção, relevância, confiança e satisfação (KELLER, 2009). Utilizaram-se também componentes de avaliação da user experience (experiência do usuário) (SAVI et al., 2010), como: imersão, desafio, habilidades e competências, divertimento, controle, interação social (GÁMEZ, 2009). Outro aspecto presente no instrumento de avaliação foi a incorporação de alguns princípios gerais da taxonomia de Bloom, visando o levantamento de informações sobre os aspectos metacognitivos relacionados ao conhecimento, compreensão e aplicação a partir da percepção do próprio aluno, sem que houvesse uma busca por levantamento de conhecimento teórico propriamente dito por meio de testes ou provas (SAVI et al., 2010). Cabe ressaltar que a avaliação da aplicação das atividades de ensino investigativo considerou tanto a percepção dos alunos como a da docente.

\section{Resultados}

Para conseguir dimensionar os impactos da aplicação da SEI na turma de $1^{\circ}$. ano da EJA-EM foi preciso levantar o contexto educacional geral. A professora regente relatou a importância de garantir a contextualização do ensino para facilitar a interpretação dos fatos reais existentes no entorno da vida dos estudantes. Apesar disso, mencionou que, em função do pouco tempo disponível para as aulas (dois encontros semanais de 45 minutos/ cada), sentia-se pressionada a trabalhar com os conteúdos do currículo de forma a priorizar os conteúdos conceituais e acabava por se utilizar de aulas do tipo expositiva-dialogada, usando basicamente giz, lousa e o livro didático do ensino regular. A docente declarou ainda se deparar, no magistério nas turmas de EJA-EM, com quatro obstáculos pedagógicos: falta de currículo mínimo, falta de material didático e suporte pedagógico, evidente defasagem conceitual e procedimental dos estudantes adultos e elevada evasão escolar (Figura 1). 
Figura 1: Mapeamento dos obstáculos pedagógicos docentes.

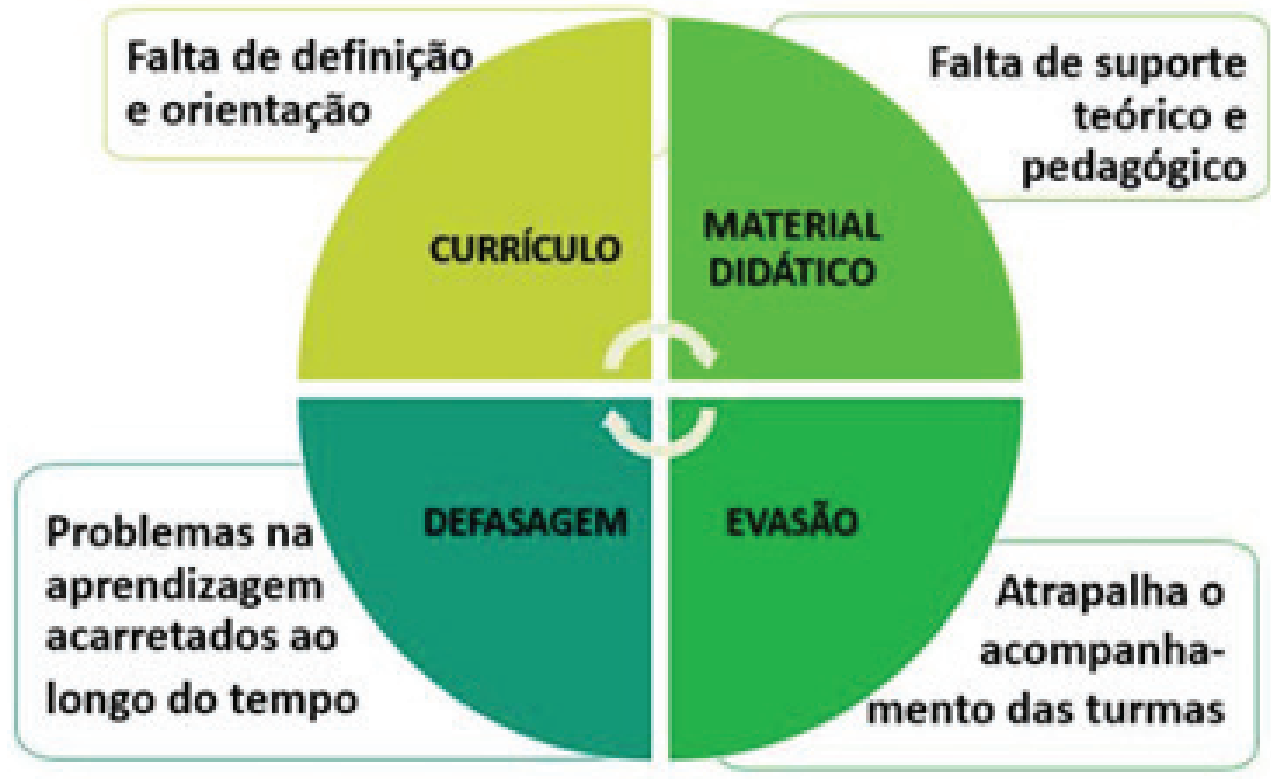

Fonte: Elaborado pelo autor.

A avaliação da aplicação da SEI, considerando a perspectiva da docente que aplicou a mesma, indica que as atividades mantiveram a atenção dos estudantes e que tinham nível de dificuldade compatível com a realidade acadêmica do grupo. Outros aspectos considerados plenamente satisfatórios se referem à relevância das atividades para a vida e realidade dos alunos, bem como, à satisfação dos mesmos na realização das propostas. Na opinião da docente, as atividades também conseguiram despertar a atenção dos alunos, oferecendo novos desafios em um ritmo apropriado, favorecendo o trabalho colaborativo e mantendo o ambiente harmonioso em sala de aula.

Para a docente, a medida do impacto da aplicação das atividades no conhecimento dos alunos mostrou que os discentes conseguiam tanto lembrar mais informações relacionadas aos temas das aulas, quanto compartilhar e aplicar essas ideias, indicando uma melhor compreensão dos temas trabalhados.

Quando consideradas as perspectivas dos alunos, os resultados apontam que a motivação para a realização das mesmas foi o ponto forte da SEI, uma vez que se evidenciou que as atividades foram capazes de promover a atenção, relevância, confiança e satisfação em efetuar as atividades (Figura 2A). Ressalta-se que grande parte dos alunos $(87,5 \%)$ considerou que as atividades não foram muito difíceis e $75 \%$ deles que a quantidade de informações fornecidas não foi um obstáculo para que eles lembrassem dos assuntos tratados.

Partindo-se da análise da satisfação dos alunos, nota-se que todos relataram ter gostado de realizar as atividades e que se sentiram bem ao completá-las. Todos os alunos declararam se sentir recompensados após receber comentários oriundos da realização das 
atividades e acreditam ter aprendido coisas surpreendentes ou inesperadas com as atividades (Figura 2A).

Figura 2: Avaliação da aplicação da SEI na perspectiva do discente.

A

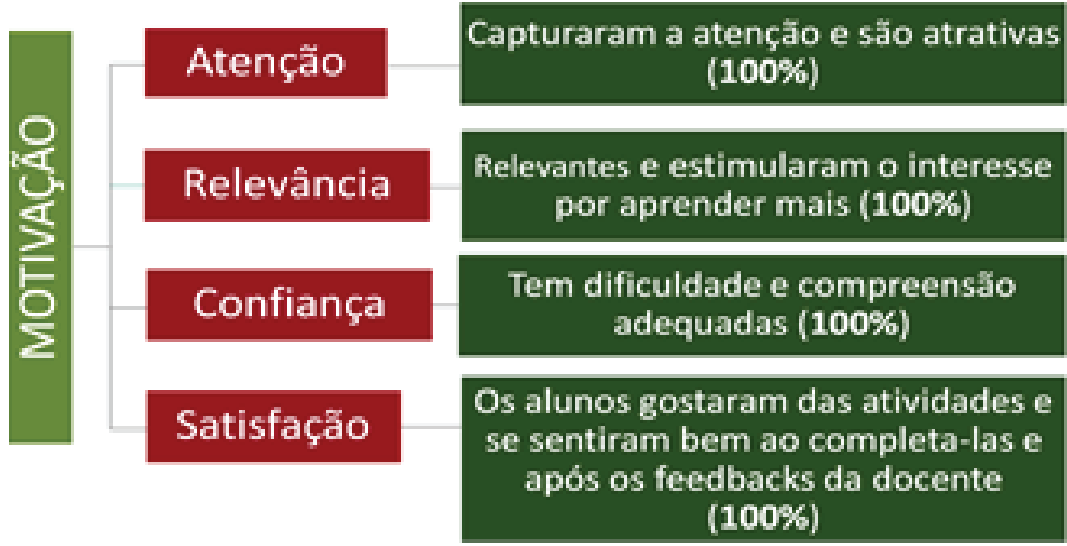

B

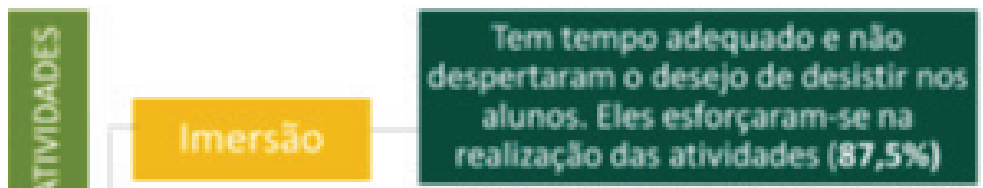

Desafios surgiram em ritmo e com

Desafíos dificuldades apropriadas. Habilidades melhoraram gradualmente (100\%)
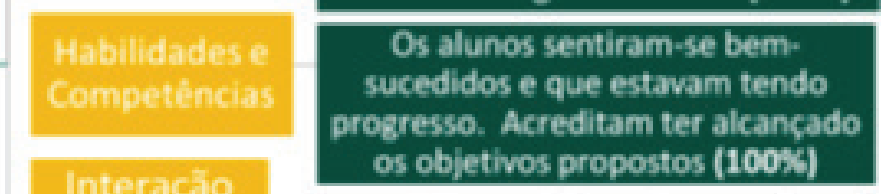

Permitiram colaboraçlo e os alunos acreditam que essas colaboraçoes auxiliaram na aprendizagem (100x)

Gostariam que ela fosse realizada novamente (100x)

$\mathrm{C}$

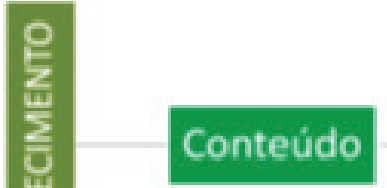

Permitiram compreender (100\%). lembrar, aplicar e utilizar melhor os conteúdos $(\mathbf{8 7}, \mathbf{5 \%})$.

Legenda: A: aspectos relacionados à motivação, B: aspectos relacionados à experiência, C: aspectos relacionados ao conteúdo.

Fonte: Elaborado pelo autor. 
Analisando-se os aspectos ligados à experiência dos estudantes na participação das atividades da SEI (Figura 2B), evidenciou-se que os alunos, de forma unânime, consideraram que: a) os desafios foram apresentados em ritmo apropriado e que as habilidades para resolvê-los melhoraram gradualmente no decorrer da SEI; b) eles percebiam e se sentiam bem com os progressos alcançados; $\mathrm{c}$ ) a oportunidade de se trabalhar de forma colaborativa facilitou a aprendizagem e d) que eles gostariam de realizar outras atividades nos moldes da SEI. O único aspecto da experiência na participação que parece merecer alguma adequação é o tempo destinado à realização da atividade, que foi apontado por $12,5 \%$ dos alunos como algo que prejudicou de alguma forma a imersão nas atividades.

Observou-se ainda que todos os alunos relataram ter compreendido bem os temas abordados na SEI e a quase totalidade dos alunos (87,5\%) indicou que seria capaz de lembrar, aplicar e utilizar melhor os conteúdos em questão (Figura 2C).

\section{Discussão}

Oliveira (1999) afirma que o aluno da EJA possui diferenças na aquisição do conhecimento, já que esse é um indivíduo adulto geralmente inserido no mundo do trabalho e que traz consigo uma carga de experiências, conhecimentos acumulados, reflexões sobre o mundo e a respeito das pessoas ao seu redor que se refletem em habilidades e, naturalmente, também em dificuldades que são distintas daquelas percebidas nas crianças e nos adolescentes. Por sua vez, a maturidade dos estudantes também garantiria uma maior capacidade potencial de reflexão acerca do conhecimento e de seus próprios processos de aprendizagem.

Nesse contexto, entende-se que o ensino por investigação poderia incorporar a ideia de pluralismo metodológico na Educação de Jovens e Adultos, pois possibilitaria que os conteúdos fossem mais motivacionais, significantes, integrados, relevantes, contextualizados e contribuiriam de forma significativa para a aquisição de habilidades relacionadas ao fazer científico (SCARPA; SILVA, 2013).

Os resultados do estudo demonstraram que, a despeito da intenção docente em realizar um trabalho direcionado ao público da EJA, a dificuldade em se garantir o cumprimento dos itens de conteúdo curricular em tempo limitado (visto que os anos letivos dessa modalidade de ensino são semestrais e não anuais como no ensino regular) acabava forçando a utilização de estratégias didáticas do tipo "aula-palestra".

Por sua vez, o desenvolvimento e aplicação de uma SEI, que contemplou os itens de conteúdo curricular e privilegiou tanto a contextualização quanto a presença dos princípios do ensino por investigação, parece ter gerado momentos pedagógicos motivadores, inspiradores e desafiadores para os alunos de EJA envolvidos nesta pesquisa. Nesse sentido, os resultados reforçam a hipótese levantada por Soares (2011) apud Barbosa (2015), de que esse tipo de abordagem poderia harmonizar a experiência individual de cada aluno da EJA aos assuntos científicos de forma mais consciente, crítica e significativa. 


\section{CONSIDERaÇões FINAIS}

Esta pesquisa mostrou que é possível desenvolver e aplicar atividades investigativas de Biologia personalizadas para a realidade social, econômica e acadêmica dos alunos das turmas da EJA-EM. Ademais, os resultados apresentados nesta pesquisa reforçam a ideia de que a incorporação curricular da SEI influenciou de maneira positiva o processo de ensino de Biologia, ampliando a motivação, a mobilização para a aprendizagem, os momentos de ensino e a compreensão dos ganhos de conhecimento por parte dos alunos envolvidos nas atividades.

Também foi possível perceber que a SEI pôde se configurar como um material didático minimamente adequado, visto que, além de auxiliar no trabalho em sala de aula, também garantiu o cumprimento dos itens curriculares conceituais sem a geração ou ampliação de insegurança na atividade profissional da docente regente da turma.

É importante pontuar que a avaliação da aplicação da sequência investigativa e a avaliação exclusivamente da SEI são independentes, já que mesmo que a aplicação não tivesse mostrado bons resultados, isso não implicaria uma desconfiguração da proposta, pois na aplicação surgem fatores diversos que poderiam influenciar no seu "sucesso". Como exemplo de alguns fatores considerados importantes na avaliação bem-sucedida dessa aplicação, cita-se: a abertura da instituição para a realização da proposta, o interesse prévio da docente e a aceitação da proposta pela turma. Provavelmente, se esses fatores não estivessem presentes no momento da aplicação, os resultados poderiam ser diferentes.

Por fim, é válido acrescentar que como o presente trabalho teve foco na análise de alguns aspectos do processo de ensino, outras pesquisas ainda serão necessárias para melhor compreender as possíveis alterações nos padrões de interação professor-aluno e nos processos de aprendizagem, especialmente aqueles relacionados às mudanças da argumentação dos discursos, entendendo-se que uma posterior análise dos roteiros decorrentes das atividades aplicadas e um olhar sobre a argumentação nos discursos dos alunos poderão fornecer subsídios para uma possível compreensão do impacto na aprendizagem.

\section{REFERÊNCIAS}

BARBOSA, J. S. e CHAGAS, P. C. M. Concepções dos alunos da Educação de Jovens e Adultos sobre a disciplina de Biologia. In: VIII Encontro Nacional de Pesquisa em Educação de Ciências (ENPEC). 8.. 2011. Rio de Janeiro, Atas... Rio de Janeiro, 2011, p. 1-13.

BARBOSA, Viviane Alves. $O$ ensino de biologia na educação de jovens e adultos: A concepção dos alunos sobre atividades investigativas e a percepção destes alunos a respeito das contribuições das atividades investigativas na aprendizagem da mitose e da meiose, 2015, 142s. Dissertação (Mestrado em Ensino de Ciências) - Instituto de Ciências Exatas e Biológicas, Universidade Federal de Ouro Preto, Ouro Preto, 2015. Disponível em: http:// www.repositorio.ufop.br/handle/123456789/5670. Acesso em: 18 jan. 2017. 
BARROW, Lloyd H. A Brief History of Inquiry: From Dewey to Standards. Journal Of Science Teacher Education, [S.I.], v. 17, n. 3, p. 265-278, 23 nov. 2006. Springer Nature. http://dx.doi.org/10.1007/s10972-006-9008-5. Disponível em: https://eclass.uoa.gr/modules/document/file.php/ECD129/Inquiry,fromDeweyfulltex.pdf. Acesso em: 22 fev. 2017.

BRASIL. Conselho Nacional de Saúde. Resolução No. 510, de 7 de abril de 2016. Trata das especificidades éticas das pesquisas nas ciências humanas e sociais e de outras que utilizam metodologias próprias dessas áreas. Diário Oficial da União, Brasília, 24 de maio de 2016. Disponível em: http://www.anped.org.br/news/novaresolucao-5102016-de-etica-na-pesquisa. Acesso em: 26 mar. 2017.

BRASIL. Ministério da Educação. Parâmetros curriculares nacionais: Ciências Naturais. Brasília, 1997. Disponível em: http://portal.mec.gov.br/seb/arquivos/pdf/ciencias.pdf. Acesso em: 10 jun. 2016.

BRASIL. Ministério da Educação. Proposta Curricular para a Educação de Jovens e Adultos: segundo segmento do ensino fundamental - Ciências Naturais. Brasília: MEC, 2001. Disponível em: http://portal.mec.gov.br/secad/arquivos/pdf/eja/propostacurricular/ segundosegment o/vol3_ciencias.pdf. Acesso em: 10 jun. 2016.

BRASIL. Ministério da Educação. Base nacional comum curricular. Brasília: MEC, 2016. Disponível em: http://basenacionalcomum.mec.gov.br/documentos/bncc2versa o.revista.pdf. Acesso em :10 jun. 2016.

CHINN, C. A.; MALHORTRA, B. A. Inquiry in schools: a theoretical framework for evaluating inquiry tasks. Science Education, S.1., 2. ed., v. 86, p. 175-218, 2002. Disponível em: http://onlinelibrary.wiley.com/doi/10.1002/sce.10001/pdf. Acesso em: 10 ago. 2016.

CUNHA, Marcus Vinicius. John Dewey: Filosofia, Política e Educação. Perspectiva, Florianópolis, v. 19, n. 2, p. 371-388, 2001. Disponível em: https://periodicos .ufsc.br/index. php/perspectiva/article/view/10235/9618. Acesso em: 11 dez. 2016.

DAMIANI, M. F. et al. (2013). Discutindo pesquisas do tipo intervenção pedagógica. Cadernos de Educação: Faculdade de Educação UFPel, Pelotas, n. 45, p. 57-67, 2013. Disponível em: https://periodicos.ufpel.edu.br/ojs2/index.php/caduc/article/view/ 3822/3074. Acesso em: 20 dez. 2017.

GÁMEZ, E. H. C. (2009). On the Core Elements of the Experience of Playing Video Games. Tese de doutorado - UCL Interaction Centre Department of Computer Science. Disponível em: http://citeseerx.ist.psu.edu/viewdoc/download?doi=10.1.1.600. 8754\&rep=rep1\&type=pdf. Acesso em: 23 mai. 2017. 
GUISASOLA, J.; FURIÓ, C.; CEREBIO, M. Science education based on developing guided research. Science Education in Focus, [S.I.], p. 56-83, 2006. Disponível em: http:// ibrarian.net/navon/paper/Editor_Mary_V_Thomase_2006_Nova_Science_Publi. pdf?paperid=16696927. Acesso em: 23 mai. 2017.

KELLER, J. M. (2009). Motivational Design for Learning and Performance: The ARCS Model Approach. Springer. Disponível em: https://link.springer.com/book/10. 1007\%2F978-1-4419-1250-3. Acesso em: 20 mai. 2017.

KRASILCHIK, Myriam. Reformas e realidade: o caso do ensino das ciências. São Paulo em Perspectiva, São Paulo, v. 14, n. 1, p.85-93, mar. 2000. Disponível em: http://www. scielo.br/pdf/spp/v14n1/9805.pdf. Acesso em: 23 mai. 2017.

MACHADO, Vera Mattos. Análise das orientações didáticas dos PCN de Ciências: enfoque sobre a problematização. Horizontes: Revista de educação, [S.I.], v. 1, n. 1, p. 87-99, jul. 2013. Disponível em: http://ojs.ufgd.edu.br/index.php/horizontes/article /view/2066/1438. Acesso em: 15 mar. 2017.

OLIVEIRA, I. B. (2007). Reflexões acerca da organização curricular e das práticas pedagógicas na EJA. Educar, Curitiba, n. 29, p. 83-100, 2007. Disponível em: http://www.scielo. br/pdf/er/n29/07.pdf. Acesso em: 14 ago. 2016.

OLIVEIRA, M. K. (1999). Jovens e adultos como sujeitos de conhecimentos e aprendizagem. In: Reunião Anual da ANPEd, 22., Caxambu, p. 01-24. Disponível em: http:// xa.yimg.com/kq/groups/20938193/216545614/name/daniele .pdf. Acesso em: 27 fev. 2017.

RONDÔNIA. Secretária do Estado da Educação. Educação de Jovens e Adultos (EJA): Ensino Fundamental e Médio. Rondônia, 2013. Disponível em: http://www.seduc.ro.gov. $\mathrm{br} /$ curriculo/wp-content/uploads/2013/02/EDUCACAO-DEJOVENS-E-ADULTOS-EJA. pdf. Acesso em: 5 jan. 2017.

SÁ, E. F. et al. (2007). As características das atividades investigativas segundo tutores e coordenadores de um curso de especialização em Ensino de Ciências. In: VI Encontro Nacional de Pesquisa em Educação em Ciências, Florianópolis. Disponível em: http:// www.nutes.ufrj.br/abrapec/vienpec /CR2/p820.pdf. Acesso em: 10 ago. 2016.

SAVI, Rafael et al. (2010). Proposta de um Modelo de Avaliação de Jogos Educacionais. Revista Novas Tecnologias na Educação, [S.I.], v. 8, n. 3, p. 1-12, dez. Disponível em: http://seer.ufrgs.br/index.php/renote/article/view/18043/ 10630. Acesso em: 11 out. 2016. 
SCARPA, D. L.; SILVA, M. B. (2013). A Biologia e o ensino de Ciências por investigação: dificuldades e possibilidades. In: CARVALHO, A. M. P. (Org.). Ensino de ciências por investigação: condições para implementação em sala de aula. São Paulo: Cengage Learning. cap. 8 .

TONIDANDEL, S. M. R. (2013). Superando obstáculos no ensino e na aprendizagem da evolução biológica: o desenvolvimento da argumentação dos alunos no uso de dados como evidências da seleção natural numa sequência didática baseada em investigação, 2013, 270s. Tese (Doutorado em Educação). Faculdade de Educação da Universidade de São Paulo, São Paulo. Disponível em: http://www.teses.usp.br/teses/ disponiveis/48/48134/ tde-18122014-100501/publico/SANDRA_MARIA_RUDELLA_ TONIDANDEL_rev. pdf. Acesso em: 24 out. 2016.

TRÓPIA, Guilherme. Percursos históricos de ensinar ciências através de atividades investigativas. Ensaio Pesquisa em Educação em Ciências (Belo Horizonte), Belo Horizonte, v. 13, n. 1, p. 121-138, abr. 2011. FapUNIFESP (SciELO). http://dx.doi.org/10.1590/198321172013130109. Disponível em: http://www.scielo. br/scielo.php?script=sci_arttext\&pid =S1983-21172011000100121. Acesso em: 2 ago. 2016.

ZÔMPERO, A. F.; LABURÚ, C.. Atividades investigativas no ensino de ciências: aspectos históricos e diferentes abordagens. Revista Ensaio, Belo Horizonte, v. 13, n. 3, p. 67-80, dez.2011 Disponível em: http://www. scielo.br/pdf/epec/v13n3/1983-2117epec-13-03-00067.pdf. Acesso em: 10 jun. 2016.

\section{DAdOS DOS AUTORES}

\section{William Kleber Martins Vieira}

Instituto de Ciências Biomédicas da Universidade de São Paulo (USP). São Paulo/SP- Brasil.williamklebermartins@gmail.com

\section{Roberta Conceição Silva Mores}

E. E. João Alvares Siqueira Bueno. Guarulhos/SP- Brasil. silva.robertac@gmail.com

\section{Martha Cristina Motta Godinho}

Instituto Federal de Educação, Ciência e Tecnologia de São Paulo (IFSP). São Paulo/SPBrasil.martha.godinho2@gmail.com

Submetido em:13-12-2018

Aceito em: 25-4-2019 